Revista Iberoamericana, Vol. LXXVII, Núm. 235, Abril-Junio 2011, 557-575

\title{
ORALIDAD Y MEMORIA COLECTIVA EN LENGUA DE PÁJARO. COMENTARIOS REALES DE NANCY MOREJÓN Y CARMEN GONCE
}

\author{
POR \\ María del Carmen Sillato \\ University of Waterloo \\ Yo, incitado del deseo de la conservación de
las antiguallas de mi patria, esas pocas que
han quedado, porque no se pierdan del todo,
me dispuse al trabajo tan excesivo como hasta
aquí me ha sido y delante me ha de ser, al
escribir su antigua república hasta acabarla.
Inca Garcilaso de la Vega
}

En el celebrado poema del chileno Pablo Neruda “Alturas de Macchu Picchu”, exclama la voz poética ante las ruinas de esa gran civilización incaica, en ese singular diálogo con los ausentes: "Yo vengo a hablar por vuestras bocas muertas [...] Hablad por mis palabras y mi sangre” (129). Esa posibilidad de "hablar" por el "otro/a” remite a la idea de un sujeto imposibilitado de hablar por sí mismo y a alguien -un mediadorque servirá de puente en el proceso de comunicación. Nos encontramos aquí ante una preocupación que, desde los años setenta en adelante, ha dominado la crítica poscolonial en torno al papel del sujeto subalterno -el desposeído económicamente, según Antonio Gramsci- y al rol del intelectual como mediador. Para los filósofos franceses Michel Foucault y Gilles Deleuze, si el subalterno tiene la posibilidad y existen condiciones de solidaridad a través de alianzas políticas, entonces puede hablar por sí mismo y conocer sus circunstancias. ${ }^{1}$ Inspirado en un momento de fuertes resonancias políticas como lo fue el mayo francés en 1968, Foucault iba a declarar: "Los intelectuales han descubierto, después de las recientes luchas, que las masas no los necesitan para saber; ellas saben perfectamente, claramente, mucho mejor que ellos; y además lo dicen muy bien” (9). A estas premisas les iba a responder Gayatri Spivak con un rotundo "el subalterno no puede hablar” a modo de conclusión de un artículo al que precisamente había titulado “¿Puede hablar el subalterno?” (104). Spivak refuta aquí lo expuesto por Foucault y

1 Ver Spivak ("Can the Subaltern” 66). 
Deleuze sobre el sujeto subalterno y el rol del intelectual y reafirma su posición acerca de que el subalterno no está en condiciones de hablar por sí mismo. En ese tránsito entre lo que Hegel denomina el "en sí" (las condiciones objetivas de existencia) y el "para sí” (apropiación de aquella existencia) es necesaria la mediación ya que el subalterno no puede hablar sólo avalado por su experiencia. ${ }^{2}$ A diferencia de Foucault y Deleuze, que veían en la mediación la repetición de una práctica autoritaria, Spivak le adjudica a esa mediación una función social (“Can the Subaltern” 66-86). Años más tarde, en 1993, durante una entrevista con Donna Laundry y Gerald McLean, Spivak menciona la interpretación errónea que en algunos casos se hizo de su artículo y el hecho de que se llegara a pensar que ella estaba proponiendo exactamente lo opuesto de lo que había intentado proponer (“Subaltern Talk” 289). Aclara, además, lo que ella había querido significar con su aseveración de que "el subalterno no puede hablar": "So, 'the subaltern cannot speak,' means that even when the subaltern makes an effort to the death to speak, she is not able to be heard; and speaking and hearing complete the speech act" ("Subaltern Talk" 292).

Los conceptos de subalternidad y mediación se corresponden con las propuestas lanzadas a partir del surgimiento y la difusión del género testimonial en Latinoamérica que tuvo en el cubano Miguel Barnet a uno de sus primeros teóricos. En 1969, en su conocido estudio “La novela-testimonio: socio-literatura”, Barnet sostiene que "la novelatestimonio debe ser un documento a la manera de un fresco, reproduciendo o recreando [...] aquellos hechos sociales que marcaran verdaderos hitos en la cultura de un país" (20). Agrega más adelante: "[L]a primera característica que entiendo debe poseer toda novela-testimonio [es] proponerse un desentrañamiento de la realidad tomando hechos principales, los que han afectado la sensibilidad de un pueblo y describiéndolos por boca de uno de sus protagonistas más idóneos” (20-21). ${ }^{3}$ Partiendo de estas discusiones,

2 Ver al respecto el análisis que de esta discusión realiza Claudia Zapata en su artículo "Michel Foucault, los intelectuales y la representación. A propósito de los intelectuales indígenas”, del cual se han tomado algunos conceptos.

3 El "descubrimiento" del relato testimonial en los Estados Unidos sería la causa y el motor del surgimiento en los ochenta de un movimiento a favor de este tipo de literatura nunca antes considerado dentro del canon de los "géneros literarios consagrados”. En su conocido artículo "Anatomía del testimonio”, John Beverley se hará eco de las premisas vertidas por Barnet definiendo el testimonio como "una narración -usualmente, pero no obligatoriamente del tamaño de una novela, o novela corta- contada en primera persona gramatical por un narrador que es a la vez el protagonista (o el testigo) de su propio relato. Su unidad narrativa suele ser una 'vida' o una vivencia particularmente significativa (situación laboral, militancia política, encarcelamiento, etc.)". Para Beverley, el testimonio se ubica en el intersticio entre las culturas del opresor y del oprimido; es una forma de la dialéctica de opresor y oprimido (9). Margaret Randall, por su parte, no sólo busca especificar la naturaleza del testimonio sino que va más allá con su propuesta acerca de cómo hacer un testimonio (elegir el tema y el o los informantes), conocer todo lo que se pueda sobre el tema (período o hechos que motivan nuestro interés en esa o esas personas), el

ISSN 0034-9631 (Impreso) 
quiero proponer aquí el análisis de un texto de gran riqueza testimonial en el que un grupo de informantes ${ }^{4}$ va trazando los hilos conductores de la historia cubana desde 1942 hasta 1959 a partir de la transmisión de historias singulares. Se trata de Lengua de Pájaro. Comentarios reales de Nancy Morejón y Carmen Gonce. ${ }^{5}$ El texto se publicó en La Habana en 1968 pero, como la misma Morejón afirma, "es un libro del cual se ha hablado poco” (“En los sitios” 21), lo que no deja de llamar la atención puesto que su aparición es inmediatamente posterior a la publicación de Biografía de un cimarrón (1966) de Miguel Barnet y un año anterior a la publicación de su artículo "La novelatestimonio: socio-literatura” (1969). ${ }^{6}$ Me interesa en principio examinar los relatos de los personajes que atraviesan estas páginas, esos “sujetos subalternos” de un periodo clave en el desarrollo de la guerra revolucionaria cubana, en relación a la respuesta con la que Spivak concluye su estudio sobre la subalternidad.

En cuanto a las motivaciones de sus autoras en la producción de un texto cercano a la historiografía, sus primeras incursiones en el área del relato testimonial se dieron de manera espontánea, sin siquiera habérselo propuesto. Sin embargo, Gonce es historiadora y en el caso de Morejón no caben dudas de que su interés por la historia ha guiado su escritura desde sus primeros intentos y ha abarcado todos los géneros incursionados. ${ }^{7}$ Para ella, la escritura ha sido siempre una herramienta útil para acercarse al otro e incluirlo en su universo poético. "En esa búsqueda incesante de la belleza [que es el acto poético]”, nos dice, "no he despreciado nada, ni a nadie. Formo parte de una familia, una comunidad, de una nación de las que no he querido ni he podido apartarme sino que las reclamo con amor en cada uno de mis gestos. El amor supone comprensión infinita y una conciencia de que somos semejantes al prójimo" (“Discurso”). No es de extrañar, entonces, que haya tenido siempre una actitud combatiente en todos los

cuestionario, el arte de la pregunta, la libreta de apuntes, la transcripción y la ética” (“¿Qué es y cómo se hace un testimonio?” 23-27).

4 El término "informante" refiere al que da testimonio y es utilizado por Barnet en la introducción a Biografía de un cimarrón (11).

5 Aunque al comienzo de este trabajo dedico algunos comentarios a Nancy Morejón en particular, en todo momento tendré presente la colaboración de ambas autoras como copartícipes en la configuración de este libro.

6 Es posible que la circulación y/o promoción limitada del texto, dada la situación de aislamiento que atravesaba Cuba en esos años después del embargo económico impuesto por los EEUU, no haya permitido su divulgación fuera de los límites del territorio nacional. El caso de Miguel Barnet había sido diferente ya que su libro había servido de base para la institucionalización del género testimonio dentro del prestigioso concurso literario de Casa de las Américas.

7 Respecto de la actividad poética de Morejón, sostiene Richard Jackson: "Her poems review history in the first person, while the person speaks about experiences common to many. Most important, her poems trace the development of the human heart, which suffers affronts and questions but, proudly, endures. These poems link history to the present" (107).

Revista Iberoamericana, Vol. LXXVII, Núm. 235, Abril-Junio 2011,
ISSN 2154-4794 (Electrónico) 
terrenos de la vida y que haya levantado su voz una y otra vez a favor de la inclusión de todos los sectores en ese fluir de un proceso revolucionario que propuso, desde sus inicios en 1959, la construcción de una sociedad igualitaria, sin diferencias de clase ni de origen. "Los cubanos", asevera, "nos caracterizamos por habernos propuesto la gestación de una nación homogénea en su misma heterogeneidad, caracterizada por un fin político (la Revolución Cubana encabezada por Fidel Castro), más allá de cualquier cándida controversia sólo cultural o racial” (Fundación de la imagen 190). Esa actitud la revela haciendo público su interés primordial por la Historia "con mayúscula” y por las historias "con minúscula”:

He buscado sin tregua darle voz a un coro de voces silenciadas que, a través de la historia, mucho más allá de sus orígenes, su raza o su género, renacen en mi idioma. Entre las elegías de Guillén y el gesto rumoroso de la poetisa güinera Cristina Ayala, ha fluido mi voz buscando un sitio entre el violín y el arco, buscando el equilibrio entre lo mejor de un pasado que nos sometió sin compasión a la filosofía del despojo y una identidad atropellada en la búsqueda de su definición mejor. Me ha importado la Historia en letras grandes y me importó la historia de abuelas pequeñitas, adivinadoras, las que bordaron el mantel donde comían sus propios opresores. Historia de látigo, migraciones y estigmas que llegaron por el mar y al mar vuelven sin razón aparente. (Discurso)

Esa "búsqueda de voces silenciadas" se remonta a sus años de juventud, a sus primeros contactos con el dolor de los otros, a su toma de conciencia de pertenencia al Tercer Mundo, a su despertar ante los verdaderos motivos de las diferencias de clase y origen y de las injusticias sociales. ${ }^{8}$

Sería difícil analizar las razones que hicieron posible el triunfo de la Revolución Cubana el 1 de enero de 1959 si no se tuviera un conocimiento cabal de aquellas circunstancias que promovieron la necesidad de un cambio político, económico y social, y la construcción de un nuevo modelo de país. Ese deseo de indagar tanto el pasado reciente como los hechos que fueron marcando a través de los siglos la identidad del pueblo cubano queda forjado en esa obra mencionada más arriba que abre una nueva manera de examinar la historia: Biografía de un cimarrón (1967). Se trata de un trabajo cercano a la etnografía, que incluye según palabras de Barnet, "[...] eso que no estaba en los libros de historia, con relación al tema negro en Cuba y la esclavitud. Fui a buscar esa magia, esa resonancia que no estaba en los documentos, que no se proyectaba en las academias, en las universidades” (“Para llegar” 32). Tomando como referencia la

8 Según Caroline A. McKenzie,“[...] the Revolution of 1959 demanded not just economic parity among Cuba's citizens but, rather, a complete transformation of the national self-image. The language surrounding identity, the names by which Cuba called itself would have new meaning, 'Third World' would not mean 'third rate.' Rather, it would signify a rich and varied culture, a historically exploited culture, within which lay the possibility of a more equitable universe" (83).

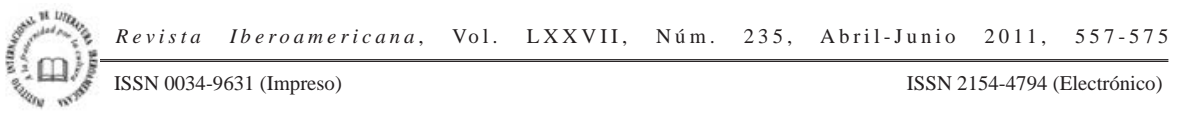


experiencia de producción de Biografía de un cimarrón y su estrecha relación con su informante Esteban Montejo, un ex-esclavo de más de cien años que había vivido acontecimientos históricos nunca antes mencionados en los textos oficiales, Barnet propone la integración de todos los sectores excluidos hasta entonces en la fundación de la identidad cubana. El gestor de la novela-testimonio, señala, "[d]ebe contribuir a articular la memoria colectiva, el nosotros y no el yo". "La historia de las gentes sin historia”, añade citando a Juan Pérez de la Riva, "ha encontrado sus portavoces en estos excavadores de la conciencia colectiva” ("Novela-testimonio” 30-31; énfasis en el original) ${ }^{9}$

En 1968, dos años después de la aparición de Biografía de un cimarrón, Nancy Morejón y Carmen Gonce llegan al poblado de Nicaro "a ejercer una suerte de activismo cultural”, para lo cual necesitaban realizar una breve encuesta sociológica. Las esperadas respuestas sobre las actividades culturales de la comunidad fueron torciendo su rumbo y para sorpresa de las encuestadoras se hizo presente el relato de la Historia a través de las "historias singulares" que exponían los encuestados, sobre todo "los más viejos y los más sedentarios”. Del resultado de estas entrevistas iba a nacer Lengua de Pájaro. Comentarios reales. Así lo recuerdan las autoras en la introducción: "Cada informante mostraba un carácter y, a la vez, una zona específica de la historia político-social de Nicaro. En algunas ocasiones encontramos informantes con una peculiar participación en todos los hechos históricos de su comunidad [...] Así, la memoria colectiva puso en función todos sus engranajes” (14).

El texto contiene: a) una introducción a cargo de Morejón y Gonce; b) tres cuerpos que reúnen relatos orales de 28 informantes, habitantes de Nicaro y trabajadores de la planta estadounidense de níquel que funcionó en esa zona entre 1942 y 1958; c) un apéndice que incluye la guía de informantes; d) una cronología histórica que abarca de 1939 a 1960, y e) un detalle de las principales etapas de producción de la planta procesadora de níquel. ${ }^{10}$ Se explica en la "Introducción" que la planta se cerró en 1947, dos años después de finalizada la Segunda Guerra Mundial, y se reabrió en 1952 durante la invasión de los EE.UU. a Corea. Respecto de la geografía del lugar, Nicaro se construye como comunidad industrial en la península Lengua de Pájaro, "un cayo cenagoso propiedad de la United Fruit Company” (9), al comenzar a explotarse por parte de compañías norteamericanas las minas de níquel. ${ }^{11}$ Explica Morejón: "Es una ciudad

9 Elzbieta Sklodowska va a criticar posteriormente este concepto subrayando que "la idea de 'darle/ tomarle’ la voz a alguien implica control, exclusión, coacción” (13).

10 Hace notar Keith Ellis que "la presencia en estas obras [de carácter testimonial] de un prólogo y de otros elementos paratextuales [...] inevitablemente enfocan cuestiones de la posible antinomia entre veracidad y presentación artística” (“Che” 332)

11 La planta de níquel de Nicaro es un recurso natural e industrial de mucha importancia para la economía cubana. Ya hacia finales del siglo xix los EE.UU. comienzan a interesarse por las riquezas minerales que existían en la zona de Mayarí. Sin embargo, no es hasta 1941, una vez descubierta la fórmula para la

Revista Iberoamericana, Vol. LXXVII, Núm. 235, Abril-Junio 2011, $557-575$
ISSN 2154-4794 (Electrónico) 
en un mundo bien alejado; por eso la cita inicial del libro es de Pablo de la Torrente Brau: 'Si quieren ir a otro país sin salir de Cuba, vayan a las montañas de Oriente'” (Morejón, “Sitios” 21).

Los relatos orales fueron recogidos en su totalidad en 1968 y conforman las dos terceras partes del libro. Primero las autoras tomaron notas posteriores a cada entrevista; más adelante consiguieron una grabadora, ${ }^{12}$ aparato desconocido en ese entonces por muchos de los entrevistados. Luego comenzó la tarea de desdoblamiento de las cintas, la transcripción al papel. Como es común en el caso de la recopilación de relatos testimoniales orales, la creatividad del transcriptor en la elaboración del texto escrito se vuelve imprescindible. En el caso concreto de una multiplicidad de voces como es el de Lengua de Pájaro, dar forma y sentido al material recogido dependía de la habilidad de quienes tenían en sus manos la tarea de configurar un relato que, aunque poblado de voces diversas, pudiera ir trazando las huellas del devenir histórico. En el momento de concretar la tarea las autoras se enfrentaron con un dilema: ¿cómo constatar la veracidad de estos testimonios en los que intervienen los juegos de la memoria, la exageración a veces, la falta de precisión? La búsqueda de documentos históricos sobre el periodo que cubren estos relatos fue poco exitosa: "Sólo pudimos hallar escasos informes, adaptados evidentemente a la estrategia económica del gobierno de Washington, y en segundas y terceras interpretaciones” (Morejón y Gonce 16). Al final de su estancia en la zona tuvieron la posibilidad de consultar el archivo del museo de la Comandancia del Segundo Frente Oriental Frank País y a través de los documentos del Ejército Rebelde pudieron corroborar lo expuesto en algunos de los relatos de los informantes, “[...] sobre todo en lo que a la etapa insurreccional se refería” (17). ${ }^{13}$ Por tal razón, la constatación de la veracidad de estos testimonios no se da gracias a un relato histórico documentado sino fundamentalmente a la ratificación constante que cada informante hace de lo expuesto por el/los anterior(es). Por ejemplo, algunos sucesos aparecen mencionados varias veces desde la óptica de diferentes informantes. Tal es el caso de la mención del asesinato de Orejón, que se convierte en un punto de referencia -un 'antes de’ o un 'después de’ que mataran a Orejón- en el relato del desarrollo de la guerrilla

purificación del níquel y debido a la decisión de entrar en la Segunda Guerra Mundial, que los EE.UU. optan por la explotación minera.

12 Opina Barnet que "[p]ara la ejecución de una obra donde [el lenguaje oral] funcione, es necesaria la grabadora, que lo escucha todo, que lo percibe todo y que es además el oído imparcial por excelencia” ("Novela-testimonio" 29).

13 Aconseja Barnet: "El gestor de la novela-testimonio tiene una sagrada misión y es la de develar la otra cara de la medalla. Para eso, lo primero que tiene que hacer es una labor previa de investigación y sondeo. Descubrir lo intrínseco del fenómeno, sus verdaderas causas y sus verdaderos efectos. [...] Yo debo primero conocer muy bien la época, sus movimientos cruciales, sus cambios, su atmósfera, para luego entrar a analizar a sus actores; si no se produce una contradicción entre lo que el protagonista cuenta, la manera en que lo cuenta y el hecho en sí” (“Novela-testimonio” 25).

Revista Iberoamericana, Vol. LXXVII, Núm. 235, Abril-Junio 2011,
ISSN 2154-4794 (Electrónico) 
rebelde. También, varios coinciden al relatar el desembarco del Corynthia, la toma de Nicaro por el Ejército Rebelde bajo el comando de Raúl Castro y la quema del poblado Levisa por parte del ejército de Batista, sin descontar las coincidencias en los informes sobre las condiciones de vida en Nicaro, la división en barrios según el estatus social o el cierre y reapertura de la planta.

Pese a la oralidad en la que se funda, Lengua de Pájaro presenta las características de documento socio-histórico. Se exponen aquí una y otra vez por boca de las/los diferentes informantes las condiciones de explotación de los trabajadores de la planta de níquel en esa zona del país durante los años de administración estadounidense. También se ponen en evidencia las razones que condujeron a las luchas en contra de la opresión y se construye ante el lector un panorama que permite visualizar el proceso que llevó a la implementación de los cambios radicales que se produjeron posteriormente con la instauración de un modelo marxista en 1959. Figuran sólo un par de documentos oficiales en la "Introducción" en los que aparece diseñada la mentalidad colonialista que dominó a la isla desde la llegada de los primeros conquistadores hasta el triunfo de la Revolución Cubana. El primer documento data de 1795 y es una carta del Conde de Jaruco a Arango y Parreño en la que se pone en evidencia el concepto colonial de propiedad de la tierra durante el imperio español, un "real pirateo de tierras" como lo indican las autoras (Morejón y Gonce 18). Dice el Conde de Jaruco al hacer referencia a "un paraje llamado Guantánamo" en la isla de Cuba:

Yo había pensado proponer formar las poblaciones por mí y a mi costa bajo condiciones muy ventajosas para mí; [...] advirtiéndote solamente que como se puedan conseguir seis u ocho leguas de tierra en aquel paraje despoblado (que según me han asegurado vale a mil pesos la legua) puedo formar un establecimiento muy útil y ventajoso a mis intereses. (18)

Bien hace notar Morejón que “[... ] tanto en la literatura de los cronistas como en la de los conquistadores, comprobamos un influjo que primero rayó en el deslumbramiento y luego se tornó en la febril codicia por poseer no sólo aquellas tierras feraces, aquellos ríos de oro, sino el espíritu, el modo de vida de sus dueños y habitantes” (Fundación 188-89). El segundo documento citado expone cómo ciento cincuenta años más tarde ese concepto colonial seguía teniendo vigencia, esta vez a través de un nuevo estado imperialista: los EE.UU. Se trata de un anuncio publicado en el New York Times el 25 de octubre de 1948 y que lleva por título: "Se vende o arrienda la compañía cubana de níquel de Nicaro”. Leemos allí:

El gobierno de los EE.UU. ofrece ahora la venta o arriendo de todos los derechos, títulos e intereses en este proyecto que es conocido como Plancor 690. El título de todas las propiedades fiscales lo tiene la Compañía Cubana de Níquel, una corporación cubana

Revista Iberoamericana, Vol. LXXVII, Núm. 235, Abril-Junio 2011,
ISSN 2154-4794 (Electrónico) 
cuyo depósito de todo su capital es propiedad del Gobierno de los EE.UU. (Morejón y Gonce 19)

Entre esas propiedades fiscales figura, “[u]n pueblo completo más de 400 casas con comodidades y servicio para unas 3,000 personas”. ${ }^{14}$ Habiendo sido el último país latinoamericano que después de largos años de lucha y tribulaciones obtuvo su independencia de España (1898), Cuba pasó de ser un estado colonial en manos de la corona española a un estado neocolonial bajo la administración de los EE.UU. que luego de ocupar militarmente la isla desde 1898 hasta 1903, dispuso de sus bienes en complicidad con los gobiernos/dictaduras de turno. ${ }^{15} \mathrm{El}$ anuncio de la venta de la planta de níquel demuestra hasta qué punto los “nuevos colonizadores” ostentaban la propiedad de las tierras y de las industrias y seguían ejerciendo el control económico del país a cincuenta años de su independencia de España y bajo el amparo en esos años de la férrea dictadura de Fulgencio Batista. Es contra ese marco histórico de omisiones y opresión que se levantan las memorias de los informantes de Nicaro. Es a través de sus memorias y gracias a esa tarea de las entrevistadoras que el lector de estos relatos ingresa a una realidad poco conocida y poco divulgada fuera de las fronteras nacionales en los años que siguieron al triunfo de la Revolución. No existe en estos relatos una intención explícita de denuncia por parte de los entrevistados, sobre todo en la primera parte del texto titulada "Lengua de Pájaro”. Se destaca, sí, el deseo de los informantes de contribuir a la reconstrucción de ese periodo de la historia cubana a partir de sus experiencias personales. El empeño de todos/as en responder a las preguntas sobre las necesidades recreativo-culturales con el relato de los sucesos históricos que les tocó vivir en la planta de níquel pone de manifiesto la conciencia que ya todos tenían al momento de las entrevistas, en 1968, del valor del aporte individual a la reconstrucción de la historia de Cuba. ${ }^{16}$

${ }^{14}$ Este último dato de las comodidades contrasta con la realidad descrita por los lugareños, sobre todo los residentes del barrio La Pasa, hacinados en barracas y teniendo que pelear por un plato de comida.

${ }^{15}$ Para una visión concisa del devenir histórico de Cuba desde las guerras de independencia hasta el presente, consultar Keith Ellis, “Cuba’s Encounter with the Changing Faces of Imperialism.” En relación a la presencia de los EE.UU. en la vida política, económica y social de la isla a partir de su independencia de España, Ellis puntualiza: "The conduct of the diplomatic excercises at the end of the war brought much more enduring humiliation to the Cubans. In a flagrant show of imperialist manners, Cuba was given no voice by the Americans in negotiating the terms of the Treaty of Paris that ended what for them was the Spanish-American War. The Americans also supervised the constitution of the Cuban Republic, and the implementation of its electoral system, giving the U.S. a continuing interventionist right to protect their interests in the country" (165).

${ }^{16}$ Ese deseo de "contarlo todo" se resume en el comentario de un informante, quien señalando la grabadora utilizada por las entrevistadoras -un aparato desconocido para él-, dijo: "para que todo salga ahí" (Morejón y Gonce 15). Este episodio nos recuerda lo comentado por Barnet en relación a Esteban

ISSN 0034-9631 (Impreso) 
No escapa al lector la alusión intertextual explícita en el título del libro a la célebre obra Comentarios reales de los Incas del peruano Inca Garcilaso de la Vega. La primera parte de esta obra se publicó en Lisboa en el año 1609; una segunda parte bajo el título Historia general del Perú fue publicada póstumamente en Córdoba, España, en 1617. El libro está basado en relatos orales de testigos de la conquista del Perú, en recuerdos de lo que el autor vio y escuchó de su madre, tíos y otros parientes y amigos de la familia durante su infancia, y en sucesos vividos por él mismo. Así lo explica su autor:

Después de haber dado muchas trazas y tomado muchos caminos para entrar a dar cuenta del origen y principio de los Incas Reyes naturales que fueron del Perú, me pareció que la mejor traza y el camino más fácil y llano era contar lo que en mis niñeces oí muchas veces a mi madre y a sus hermanos y tíos y a otros sus mayores acerca de este origen y principio, porque todo lo que por otras vías se dice de él viene a reducirse en lo mismo que nosotros diremos, y será mejor que se sepa por las propias palabras que los Incas lo cuentan que no por las de otros autores extraños. (36)

Para el Inca Garcilaso el presupuesto de veracidad era fundamental en su deseo de ser fiel a la historia de la civilización incaica. El vocablo "reales" presente en el título es polisémico y remite tanto a la realeza incaica que en muchos casos se describe como a la veracidad de lo relatado en contraposición a los relatos ficcionales de algunos cronistas. Previendo críticas futuras, el autor buscó en todo momento corroborar con cuanto documento histórico llegara a sus manos lo que sus memorias le dictaban. Dice en el "Proemio al lector":

En el discurso de la historia protestamos la verdad de ella, y que no diremos cosa grande que no sea autorizándola con los mismos historiadores españoles que la tocaron en parte o en todo; que mi intención no es contradecirles, sino servirles de comento y glosa y de intérprete en muchos vocablos indios, que, como extranjeros en aquella lengua, interpretaron fuera de la propiedad de ella, según que largamente se verá en el discurso de la historia, la cual ofrezco a la piedad del que la leyere. (5-6)

Se le ha negado en varias ocasiones a la obra del Inca Garcilaso el valor de documento histórico que innatamente conlleva y se le ha reprochado una dosis de exageración y fantasía en su relato. No obstante, es éste el intento más importante de dejar asentadas para las generaciones venideras las tradiciones y el acervo cultural del imperio incaico. Más allá de las críticas, su libro recupera para la Historia la riqueza de una cultura que sin su intervención y documentación escrita se hubiera perdido para siempre. Sin duda, Morejón y Gonce encontraron en los Comentarios reales de los Incas un motivo de

Montejo cuando dice de él: "Miraba insistentemente hacia nuestra libreta de apuntes, casi nos obligaba a recoger todo lo que decía” (Biografía 11).

Revista Iberoamericana, Vol. LXXVII, Núm. 235, Abril-Junio 2011,
ISSN 2154-4794 (Electrónico) 
inspiración para su propio trabajo de recolección de fuentes orales y reconocieron esa deuda con el peruano en el guiño intertextual del título. Como el Inca Garcilaso, ellas también tuvieron que dejar de lado la perspectiva racional y objetiva exigida en el relato de la Historia para dar cabida a ese estilo tan propio de sus informantes de reconstruir los eventos históricos "en una manera de maravilla épica” (15). Así lo comentan en la Introducción: “¿Cómo íbamos a encasillar en nuestros criterios historiográficos, en frías encuestas y en apretadas preguntas, el testimonio oral de aquellos individuos que por primera vez reflexionaban ante sus propias vidas, al reconocerse como 'sociedad', al narrar con una cierta dosis de exageración [...] cada acontecimiento histórico?” (14-15). Esas historias singulares -“historias con minúsculas"-, constituyen la materia prima de un relato histórico que aporta de manera definitiva no sólo al conocimiento de los hechos acaecidos en un determinado lugar y en un periodo específico de la historia cubana, sino fundamentalmente al análisis de un proceso que deja en evidencia los pasos a seguir en ese camino que conduce a un pueblo en estado colonial/neocolonial hacia el logro de su liberación nacional. No es de extrañar, entonces, la presencia en el texto de Frantz Fanon, el médico psiquiatra de La Martinica, cuyo conocido estudio Los condenados de la tierra (1961), basado en su conocimiento y en su experiencia durante a la lucha insurreccional argelina en contra del poder colonizador de Francia, ha sido de gran influencia en los posteriores procesos de liberación. Desde las notas a pie de página, tal como se presentan en Lengua de Pájaro, Fanon construye el marco de referencialidad necesario para inscribir y ratificar los relatos testimoniales. A él aluden las autoras de la siguiente manera: "Hemos querido interrumpir el discurso de los tres informantes con citas tomadas de Los condenados de la tierra, porque ningún criterio nuestro podría resumir mejor, ni podría denunciar, esos fenómenos que se encuentran ocultos en las sociedades semicoloniales, tan magistralmente estudiadas por Frantz Fanon" (21). ${ }^{17}$ En las citas elegidas por las autoras, Fanon expone las diferencias abismales entre la "zona habitada por los colonos" y la "ciudad del colonizado"; la primera es "una ciudad iluminada, asfaltada, donde los cubos de basura están siempre llenos de restos desconocidos, nunca vistos, ni siquiera soñados" y la segunda es una "ciudad hambrienta, hambrienta de pan, de carne, de zapatos, de carbón, de luz” (Morejón y Gonce 84, 87). Dice uno de los informantes en relación a esa "ciudad del colonizado":

${ }^{17}$ En "Remembering Fanon”, Homi Bhabha también expresa su reconocimiento a este pensador del siglo xx: "It is such a memory of the history of race and racism, colonialism and the question of cultural identity, that Fanon reveals with greater profundity and poetry than any other writer. What he achieves, I believe, is something far greater: for in seeing the phobic image of the Negro, the native, the colonized, deeply woven into the psychic pattern of the West, he offers the master and slave a deeper reflection of their interpositions, as well as the hope of a difficult, even dangerous, freedom” (122).

ISSN 0034-9631 (Impreso) 
[L]as barracas de yaguas y guano pasaban la noche sumergidas en la mayor lobreguez; tenían por todo alumbrado un farolito de tenue luz que el barraquero colocaba cerca de su cama [...] Como esas barracas eran de carácter provisional o las contrataron personas que querían el máximum de utilidad con el mínimo esfuerzo, fue tan defectuosa su cobija, que al caer el primer aguacero, después de algunas semanas de sequía, se mojaban todas las literas de arriba y con la agravante de que el agua no podía hacer distinción entre el hombre que gozaba de perfecta salud y el que padecía de un fuerte ataque catarral. (52)

En Los condenados de la tierra Fanon realiza un profundo análisis de las condiciones que perpetúan la dependencia colonial del Tercer Mundo y expone sus propuestas concretas en el proceso de reconocimiento y autoliberación de los pueblos oprimidos.

Otro protagonista al que remiten las autoras, imprescindible en el desarrollo de la guerra revolucionaria cubana, es el comandante Ernesto "Che” Guevara. Su palabra, como la de Fanon, se integra al cuerpo del texto a través de las notas a pie de página en la tercera parte, titulada "Los nómadas armados (1956-1959)". Es pertinente la presencia del Che en esta tercera parte ya que es aquí donde se describe el comienzo de la insurrección y el reclutamiento paulatino de los pobladores en las filas de la guerrilla rebelde..$^{18}$ Por otra parte, el Che había dado su ejemplo asentando sus memorias en varias obras de carácter testimonial sobre los acontecimientos vividos durante la guerra revolucionaria. Su Obra Revolucionaria aparece citada en varias ocasiones por Morejón y Gonce para confirmar algunos datos históricos aportados por sus informantes o para recordarnos cuál debe ser la conducta de un combatiente guerrillero. El Che era consciente de que en la mayoría de los casos la inscripción de esos sucesos en el devenir histórico dependía del "buen uso" de la memoria. En el prólogo a Pasajes de la guerra revolucionaria dice: "[M]uchas veces los jefes de la [Revolución] manifestaron [...] sus deseos de hacer esta historia, pero los trabajos son múltiples, van pasando los años y el recuerdo de la lucha insurreccional se va disolviendo en el pasado sin que se fijen claramente los hechos que ya pertenecen, incluso, a la historia de América” (7). Por eso advierte a quienes quieran aportar sus testimonios sobre el carácter primordial de veracidad que debía guiar sus relatos:

Muchos sobrevivientes quedan de esta acción y cada uno de ellos está invitado a dejar también constancia de sus recuerdos para incorporarlos y completar mejor la historia. Sólo pedimos que sea estrictamente veraz el narrador; que nunca para aclarar una posición personal o magnificarla o para simular haber estado en algún lugar, diga algo

${ }^{18}$ El Che no había tenido oportunidad de conocer el pueblo de Nicaro durante la insurgencia pero conocía bien su historia y la riqueza de su industria minera. Por eso pronuncia allí su segundo discurso -20 de enero de 1961- en el que recalca la importancia de la fábrica de níquel en el sector industrial del país y la necesidad de producir más en momentos en que Cuba se sentía amenazada por los EE.UU.

ISSN 0034-9631 (Impreso) 
incorrecto. Pedimos que, después de escribir algunas cuartillas en la forma en que cada uno lo pueda, según su educación y su disposición, se haga una autocrítica lo más seria posible para quitar de allí toda palabra que no se refiera a un hecho estrictamente cierto, o en cuya certeza no tenga el autor una plena confianza. (8)

Para el Che, era esencial que la historia de la lucha revolucionaria en Cuba quedara registrada, no sólo como memoria histórica de ese país sino también como guía e inspiración para otros pueblos comprometidos en la lucha por la liberación nacional. De ahí su insistencia en el carácter fidedigno de los aportes individuales a la construcción de la memoria colectiva. Por eso, la grandeza de su obra radica en el hecho de que se recopilan allí tanto los triunfos como los fracasos propios de todo proceso de liberación. El relato de la derrota sufrida por la guerrilla el 5 de diciembre de 1956 en Alegría de Pío a tres días del desembarco del Gramma, en la cual el Che casi pierde la vida, es en esencia una autocrítica sobre ciertos errores de evaluación, impensables en guerrilleros de su experiencia pero asimismo aleccionadores. El error mayor que provocó el desastre fue haber confiado plenamente en el guía, “el autor principal de la traición” (17). Sin embargo, el Che reconoce que ese error no fue único ni aislado sino que se repitió "algunas veces durante la lucha, hasta aprender que los elementos de la población civil cuyos antecedentes se desconocen deben ser vigilados siempre que se esté en zonas de peligro” (17). En Lengua de Pájaro se menciona un episodio similar al protagonizado por el Che y sus compañeros en diciembre de 1956: el desembarco del Corynthia. Las memorias de los informantes sobre este suceso se verifican en las palabras del Che, citado en la nota a pie de página: "Pocos meses después, en mayo, se intentaba un desembarco que probablemente haya sido entregado antes de partir de Miami, pues era financiado con los dineros del traidor Prío y cuyo resultado fue una masacre casi completa de los participantes. Se trata de la expedición del Corynthia” (145). Llevando adelante la tarea de recopilar los testimonios de los habitantes de Nicaro, Morejón y Gonce se hacen eco del deseo expresado por el Che de "hacer una historia de nuestra Revolución que englob[e] todos sus múltiples aspectos y facetas” (7). Su presencia en estas páginas es una prueba del respeto y reconocimiento de las autoras hacia una de las figuras centrales de la Revolución Cubana. ${ }^{19}$

Antes de concluir quisiera retomar la discusión sobre la posibilidad de hablar o de hacerse escuchar que le cabe al sujeto subalterno y sobre el rol del intelectual como intermediario, según lo manifestado por Gayatri Spivak. El Grupo Latinoamericano de

\footnotetext{
19 En el momento de comenzar la recolección de los testimonios de los habitantes de Nicaro en febrero de 1968, Ernesto Che Guevara acababa de ser asesinado (octubre de 1967) por el ejército boliviano con el apoyo de la CIA (Central Intelligence Agency). No sería desacertado pensar que las autoras hayan elegido incluir sus palabras en Lengua de Pájaro además como homenaje de su entrega a la causa revolucionaria y como una manera de mantener viva su presencia.

Revista Iberoamericana, Vol. LXXVII, Núm. 235, Abril-Junio 2011,
ISSN 0034-9631 (Impreso)
} 
Estudios Subalternos ${ }^{20}$ sostiene en su "Manifiesto Inaugural” que el subalterno es "un sujeto mutante y migrante”, y agrega:

Aun si concordamos básicamente con el concepto general del subalterno como masa de la población trabajadora y de los estratos intermedios, no podemos excluir a los sujetos “improductivos", a riesgo de repetir el error del marxismo clásico respecto al modo en que se constituye la subjetividad social. Necesitamos acceder al vasto y siempre cambiante espectro de las masas: campesinos, proletarios, sector formal e informal, subempleados, vendedores ambulantes, gentes al margen de la economía del dinero, lumpen y ex-lumpen de todo tipo, niños, desamparados, etc. (“Manifiesto” 6) ${ }^{21}$

Estos conceptos remiten nuevamente a Frantz Fanon, para quien el "condenado de la tierra” no sólo era el proletario tal como lo definía Karl Marx sino también el "lumpen” o el marginado social por razones de diversa índole. John Beverley afirma por su parte que "[l]a subalternidad es una identidad relacional más que ontológica -es decir, se trata de una identidad (o identidades) contingente y sobredeterminada" (Writing 33). También Ileana Rodríguez, en concordancia con Fanon, sostiene que “[...] subalternidad es un término genérico que abarca clase, género, casta, oficio, etnia, nacionalidad, edad, cultura y orientación sexual” (104).

Durante los años de administración estadounidense de la planta, los habitantes de Nicaro eran en su casi mayoría sujetos subalternos migrantes, desplazados hacia esa zona del país en busca de fuentes de trabajo. A pesar de que en general estos sujetos constituían la gran masa proletaria, también convivían allí desocupados y madres solas con sus hijos en estado de gran indigencia. Esa masa proletaria, por otra parte, estaba subdividida entre los habitantes de La Pasa y los de Dos, alejados todos ellos física y socialmente de la zona habitada por el "colono" -la administración enviada desde los EE.UU.-. Así lo explica uno de ellos:

Nicaro estaba dividido en tres barrios: La Pasa era el barrio más pobre, yo viví en ese porque yo era uno de los pobres; el Dos que era de los capataces y esas cosas y esta otra parte eran los ingenieros, y Cabal donde vivían los americanos. Allí en Cabal después de las seis de la tarde no se podía entrar, ni caminar por ahí, porque los señores no querían que camináramos. (95)

${ }^{20}$ Entre los integrantes de este Grupo figuran Norma Alarcón, Julio Ramos, John Beverley, María Milagros López, Walter Mignolo y Patricia Seed. Explican sus iniciadores que "[e]l trabajo del Grupo de Estudios Subalternos, una organización interdisciplinaria de intelectuales sudasiáticos dirigida por Ranajit Guha, nos ha inspirado a fundar un proyecto similar dedicado al estudio del subalterno en América Latina” ("Manifiesto" 1).

${ }^{21}$ Cito aquí la edición del manifiesto recopilado en Teorías sin discip;lina. Latinoamericanismo, poscolonialidad y globalización en el debate, ed. Santiago Castro-Gómez y Eduardo Mendieta. Puede consultarse también en <http://www.ensayistas.org/critica/teoria/castro/manifiesto.htm>.

Revista Iberoamericana, Vol. LXXVII, Núm. 235, Abril-Junio 2011,
ISSN 2154-4794 (Electrónico) 
Según cuentan los informantes, el obrero que osaba desafiar el orden con una respuesta "inapropiada" o una llegada tarde o que cometía una distracción, como ingresar a la zona del colono, era despedido de inmediato. Las más de las veces, a esos atropellos e injusticias se les respondía con el silencio. Para Fanon, una de las formas que los desposeídos tienen de romper con el silencio es la violencia en contra del orden establecido por las esferas de poder. Las condiciones de absoluta dependencia socio-económica creadas en Nicaro por la compañía estadounidense y mantenidas por más de dieciséis años sólo comenzaron a ceder ante la creciente presión de los grupos rebeldes. En palabras de Fanon:

[1]a descolonización [...] es un proceso histórico: es decir, queno puede ser comprendida, que no resulta inteligible, traslúcida a sí misma, sino en la medida exacta en que se discierne el movimiento historizante que le da forma y contenido. La descolonización es el encuentro de dos fuerzas congénitamente antagónicas que extraen precisamente su originalidad de esa especie de sustanciación que segrega y alimenta la situación colonial. (25-26)

Según lo expresado por los informantes de Lengua de Pájaro, ese proceso de descolonización comienza a desenvolverse en la zona con la presencia del movimiento 26 de Julio, esa "fuerza antagónica" que creará las condiciones necesarias para la implementación de los primeros actos de rebeldía.

La afirmación de Spivak respecto a la voz del subalterno se confirma en las memorias de los habitantes de Nicaro durante la administración estadounidense de la planta de níquel: el subalterno en condiciones de explotación y desde ese lugar marginal al que lo somete la clase dominante en una injusta relación de fuerzas "no puede hablar", o mejor dicho, no puede reclamar por sus derechos so pena de recibir mayores castigos. Asevera John Beverley que cuando Gayatri Spivak reclamó que el subalterno no podía hablar, ella trataba de decir que el subalterno no puede hablar en una manera que conlleve cualquier forma de autoridad o sentido para nosotros, sin alterar las relaciones de poder/ saber que lo constituyen como subalterno (Writing 31). A los habitantes de Nicaro se les negó la voz en los largos años de trabajo para la compañía estadounidense, es decir, estuvieron excluidos del discurso público dominante. El silencio del sujeto subalterno era esencial para garantizar el orden impuesto. De ahí que sólo a partir de 1956, cuando la relación de fuerzas empieza a alterarse a través de un proceso revolucionario, esos "sujetos silenciados" encuentran en el compromiso y la participación en las luchas por la liberación las herramientas para rebelarse y expresar así su disconformidad con el sistema. Dice un informante:

Yo me alcé cuando tenía dieciséis años, a principios del 58. Aquí había un sargento que se llamaba Cerdeño. Ese hombre entró al carro de nosotros los obreros. Venía mi papá

\footnotetext{
Revista Iberoamericana, Vol. LXXVII, Núm. 235, Abril-Junio 2011, $557-575$
ISSN 2154-4794 (Electrónico)
} 
sentado al lado mío y más compañeros de trabajo; en eso pidieron "chapa a la vista”. Yo traía la chapa mía en la gorra. Yo no tenía que enseñársela porque estaba puesta en la gorra. El sargento se tiró arriba de mí, me agarró por el pelo, me sacudió, me regó. El viejo mío lo miraba, un amigo de mi papá lo tocó para que no dijera nada. Allí me ultrajó en palabras, me sacudió dos o tres veces, me dio palmetazos por la espalda, donde estaba el asiento. Ahí empezó ya la rebeldía mía con la tiranía batistiana. Como a los quince días empecé a trabajar en la milicia clandestina. (Morejón y Gonce 172)

Años más tarde y ya en pleno gobierno de la Revolución, esas voces se van a articular para exponer en palabras ante dos jóvenes intelectuales-Morejón y Gonce-con anotador y grabadora en mano, las memorias de sus experiencias en aquellos años de hostigamiento y explotación. Esa doble actividad, el hablar de los informantes -sujetos subalternos- de Nicaro y el escuchar/escribir de las intermediarias/transcriptoras reinscribe el canon de la literatura testimonial propuesto por Barnet. Para Barnet, Esteban Montejo [era] "un modelo ideal” de informante puesto que "[...] reunía dos condiciones necesarias para la novela-testimonio: era un personaje representativo de una clase, de un pensamiento, y había vivido momentos únicos en la historia de Cuba que marcaban la psicología de todo un conglomerado humano" ("Novela-testimonio" 32). Respecto al editor o "gestor de la novela-testimonio", afirma Barnet que éste debe "contribuir al conocimiento de la realidad, imprimirle a ésta un sentido histórico [...]"; "El gestor de la novela-testimonio [...]" (23) que "[...] debe otorgarle a sus personajes ese dinamismo, porque la memoria articulada, la conciencia de época, que son objetivos muy específicos del género, exigen un exponente genuino, convincente, no una criatura manejada por mecanismos artificiosos" ("Novela-testimonio" y 28). Como se mencionó al comienzo de este trabajo, también Spivak reconoce en su artículo "Can the Subaltern Speak?” la importancia de la presencia de un mediador en el proceso de comunicación de experiencias de opresión política y social, ya que el subalterno, aunque lo intente, no podrá hacerse oír mientras se perpetúe su posición como tal. Sin embargo, en la citada entrevista con Donna Laundry y Gerald McLean, Spivak critica la posición adoptada por ciertos intelectuales a los que llama "the remarkable organic intellectuals": "[t]he effort involved in those singular figures becoming organic intellectuals is completely undone in their positioning as 'the' subalterns [...]. The effort required for the subaltern to enter into organic intellectuality is ignored by our desire to have our cake and eat it too; that we can continue to be as we are, and yet be in touch with the speaking subaltern" ("Subaltern Talk" 292). De igual manera, los integrantes del Grupo Latinoamericano de Estudios Subalternos coinciden en afirmar que,

[a]l conceptualizar la subalternidad debemos, por ello, tener mucho cuidado en no colocarnos a nosotros mismos en la posición de letrados subalternos [...], es decir, en la posición de transcriptores, traductores, intérpretes o editores; de evitar, en otras

\footnotetext{
Revista Iberoamericana, Vol. LXXVII, Núm. 235, Abril-Junio 2011,
ISSN 2154-4794 (Electrónico)
} 
palabras, la construcción de una intelligentsia poscolonial ubicada en los centros culturales hegemónicos. Con esto no queremos obviar el problema, sino simplemente indicar que permanecer enfocados en la actividad de la intelligentsia y en sus prácticas características (centradas en el cultivo de la escritura, la ciencia, etc.) nos dejaría todavía en aquel espacio de "ceguera” y de prejuicio historiográfico que Guha criticara en sus estudios sobre la insurrección campesina. ("Manifiesto” 6)

Para Ellis, “[e]n todos [los] casos en los que se sitúa un intermediario entre el testigo y el lector, la discreción de aquél, el alcance y la calidad de su intervención, su evidente capacidad para respetar a la vez las expectativas estéticas del lector y la autenticidad del informe, la fiabilidad tanto del testigo como del escritor, se ponen a prueba” (“Che” 332). Ellis hace referencia a la relación testimoniante-intelectual letrado que caracterizó la producción de reconocidos relatos testimoniales, sobre todo en la década del ochenta, pero aplican igualmente a la relación de Barnet con su informante, Esteban Montejo, y a la relación entre las mediadoras Morejón y Gonce y los informantes de Nicaro. En estos últimos ejemplos, esa relación nace en forma natural, sin haber mediado la intención previa de elaboración de un texto testimonial. Morejón y Gonce no se imponen ante los informantes como intermediarias letradas, sino que son revestidas de esa función por los mismos informantes quienes, aprovechándose de su capacidad para escuchar, comparten con ellas los avatares que les tocó vivir en ese rincón del país. Además, reconocen la habilidad intelectual de las entrevistadoras para transcribir y difundir por escrito esos aportes y buscan así contribuir al proyecto de revisión de la historia. Más que representar al intelectual letrado que “da voz a los sin voz”, Morejón y Gonce están allí "para escuchar” ya que, como bien puntualizara Spivak, el "escuchar” es imprescindible para que el acto del habla se complete. En el momento de producción de Lengua de Pájaro ya no existían en Cuba las condiciones de explotación y hostigamiento que habían caracterizado a la Cuba de Fulgencio Batista. Contra las urgencias que caracterizarán la posterior producción de otros testimonios en Latinoamérica, ${ }^{22}$ se publica Lengua de Pájaro. Cometarios reales en un país en donde el subalterno ha dejado de serlo para convertirse en un miembro activo de esa nueva sociedad en construcción. Por eso, los testimonios de los informantes de Nicaro -como el del cimarrón Esteban Montejo- se presentan como aportes a la reconstrucción de la memoria histórica y cumplen con la función de develar los objetivos y los mecanismos que conducen a un pueblo oprimido

${ }^{22}$ Me refiero al carácter de urgencia mencionado por René Jara y Hernán Vidal que marcara, entre otros, el testimonio de la guatemalteca Rigoberta Menchú, el de la boliviana Domitila Barrios, el del chileno Hernán Valdés o el de la argentina Alicia Partnoy. Esa urgencia tenía que ver con la necesidad de inmediata difusión de las circunstancias de represión que se estaban perpetrando en esos momentos en sus países de origen para que, a través de la solidaridad internacional, se pusiera fin a los atropellos contra los derechos humanos.

\footnotetext{
ISSN 0034-9631 (Impreso)
} 
hacia el logro de su liberación nacional. ${ }^{23}$ De ahí la pertinencia de las palabras de Miguel Barnet con las que Morejón y Gonce cierran la introducción de su texto:

América requiere de la obra de fundación. América necesita conocerse, sustentarse. Junto a la corriente rica de la ficción, las obras de testimonio deben ir de la mano, rescatando, escudriñando, la enmarañada realidad latinoamericana. Es una búsqueda fatigosa pero inevitable. [...] La tradición se compone de todos los bienes espirituales del hombre. Un pueblo sin tradición es como un árbol sin hojas, un pueblo sin memoria es un pueblo desvalido. (Morejón y Gonce 23; Barnet, “Novela-testimonio” 39)

A cuarenta años de su publicación, Lengua de Pájaro. Comentarios reales conserva su vigencia y su valor como aporte testimonial a la revisión de la historia cubana. Los años de opresión en Nicaro durante la administración estadounidense, el proceso lento pero firme de concientización de los obreros de la planta de níquel y su participación activa en la lucha revolucionaria se presentan aquí como eslabones de esa cadena de acontecimientos que promovieron los cambios radicales que tuvieron efecto en la isla a partir de 1959. Las memorias de los testigos vivenciales dan cuenta del pasado neocolonial de Cuba en los años que siguieron a su independencia de la corona española, y rescatan para el lector la ideología y las nuevas estructuras que comenzaron a regir el devenir histórico del país con el advenimiento de la Revolución.

${ }^{23}$ Leemos en el ya citado "Manifiesto inaugural”: "La revolución cubana representó una recuperación parcial del impulso hacia la emergencia del subalterno, en particular gracias al acento que otorgó al problema del carácter no europeo (o post-europeo) de los sujetos sociales en América Latina en el contexto de la descolonización, levantándose así frente a la primacía de la historiografía eurocéntrica y frente a los paradigmas culturales establecidos. La relectura que hizo Roberto Fernández Retamar de Franz Fanon y del discurso de liberación nacional en su ensayo Calibán es ejemplo de una nueva conceptualización de la historia y la identidad latinoamericanas” (2).

Revista Iberoamericana, Vol. LXXVII, Núm. 235, Abril-Junio 2011,
ISSN 2154-4794 (Electrónico) 
BiBLIOGRAFÍA

Bhabha, Homi. “Remembering Fanon”. Colonial Discourse and Post Colonial Theory. Patrick Williams y Laura Chrisman, eds. New York: Columbia UP, 1994. 112-23.

Barnet, Miguel. Biografía de un cimarrón. Buenos Aires: Galerna, 1968. "La novela testimonio: socio-literatura". La fuente viva. La Habana: Letras Cubanas, 1998. 9-40.

“Para llegar a Esteban Montejo: los caminos del Cimarrón”. Contracorriente 6/2 (1996): 29-44.

Beverley, John. “Anatomía del testimonio”. Revista de Crítica Literaria Latinoamericana 13/25 (1987): 7-16.

"Writing in Reverse: The Subaltern and the Limits of Academic Knowledge." Subalternity and Representation: Arguments in Cultural Theory. Durham: Duke UP, 1999. 25-40.

Ellis, Keith. “Che, también hombre deletras”. Revista Canadiense de Estudios Hispánicos. XXIV/2 (2000): 323-41.

"Cuba's Encounter with the Changing Faces of Imperialism.” The New World Order. Gordana Yovanovich, ed. Montreal: McGill-Queen’s UP, 2003. 160-77.

Fanon, Frantz. Los condenados de la tierra. Julieta Campos, trad. México: Fondo de Cultura Económica, 1965.

Foucault, Michel. Un diálogo sobre el poder y otras conversaciones. Madrid: Alianza, 1988.

Guevara, Ernesto “Che”. Pasajes de la guerra revolucionaria. La Habana: Arte y Literatura, 1972.

Jara, René y Hernán Vidal, eds. Testimonio y literatura. Minneapolis: Institute for the Study of Ideologies and Literature, U of Minnesotam, 1986.

Jackson, Richard. “Nancy Morejón, the 'New Woman’ in Cuba, and the First Generation of Black Writers of the Revolution.” Singular Like a Bird. The Art of Nancy Morejón. Miriam DeCosta-Willis, ed. Washington, D.C.: Howard UP, 1999. 103-13.

“Manifiesto inaugural”. Santiago Castro-Gómez, trad. Teorías sin disciplina. Latinoamericanismo, poscolonialidad y globalización en debate. Santiago CastroGómez y Eduardo Mendieta, eds. México: Miguel Angel Porrúa, 1998.

McKenzie, Caroline A. "Language, Culture, and Consciousness in the Poetry of Nancy Morejón.” Singular like a Bird. The Art of Nancy Morejón. Miriam DeCosta-Willis, ed. Washington: Howard UP, 1999. 83-101.

Morejón Nancy. “En los sitios de Nancy Morejón”. Entrevista por María Grant. Opus Habana V/1 (2002): 16-25.

Fundación de la imagen. La Habana: Letras Cubanas, 1988, Discurso de aceptación del Premio Nacional de Literatura 2001. Feria Internacional

Revista Iberoamericana, Vol. LXXVII, Núm. 235, Abril-Junio 2011, $557-575$
ISSN 2154-4794 (Electrónico) 
del Libro. Ministerio de Cultura. La Habana. 12 feb. 2002. <www.afrocubaweb. com/nancymorejon.htm>. 12 dic. 2010.

y Carmen Gonce. Lengua de Pájaro. Comentarios reales [1971]. Santiago de Cuba: Oriente, 2002.

Neruda, Pablo.Antología poética. Rafael Alberti, sel. y pról. Madrid: Epasa-Calpe, 1985.

Randall, Margaret. “¿Qué es y cómo se hace un testimonio?” Revista de Crítica Literaria Latinoamericana 18/36 (1992): 21-45.

Rodríguez, Ileana. "Hegemonía y dominio: subalternidad, un significante flotante”. Teorías sin disciplina. Latinoamericanismo, poscolonialidad y globalización en debate. Santiago Castro-Gómez y Eduardo Mendieta, eds. México: Miguel Ángel Porrúa, 1988. 101-20.

Sklodowska, Elzbieta. Testimonio hispanoamericano. Historia, teoría, poética. New York: Peter Lang, 1992.

Spivak, Gayatri C. “Can the Subaltern Speak?” Colonial Discourse and Post Colonial Theory. Patrick Williams y Laura Chrisman, eds. Nueva York: Columbia UP, 1994. 66-111.

"Subaltern Talk. Interview with the Editors (1993)". The Spivak Reader. Donna Landry y Gerald MacLean, eds. Nueva York: Routledge, 1996.

Vega, Garcilaso de la. Comentarios reales de los Incas. Caracas: Biblioteca Ayacucho, 1976.

Zapata, Claudia. "Michel Foucault, los intelectuales y la representación. A propósito de los intelectuales indígenas". Cyber Humanitatis 35 (2005). <http://tinyuri. com/4cy6kz7> 22 feb. 2011.

Revista Iberoamericana, Vol. LXXVII, Núm. 235, Abril-Junio 2011, $557-575$
ISSN 2154-4794 (Electrónico) 
